\section{O papel central da criança em seus cuidados em saúde sob o enfoque dos direitos humanos dos pacientes}

\section{Eler, Kalline Carvalho Gonçalves}

Doutoranda em Bioética pela Universidade de Brasília. Email: kallinecarvalho@hotmail.com

\section{Oliveira, Aline Albuquerque Sant'Anna}

Programa de Pós-Graduação em Bioética da Universidade de Brasília.

PALAVRAS-CHAVE: Criança, Paciente, Bioética, Direitos Humanos

Introdução. A criança, de acordo com o referencial dos Direitos Humanos, é uma pessoa com habilidade decisional em evolução e, embora sua autodeterminação não seja completamente articulada, em razão da sua imaturidade e dependência, não é inexistente, antes merece ser reconhecida e valorizada. Enquanto sujeito de direitos, a criança é titular de direitos específicos no âmbito dos cuidados em saúde dos quais se destacam os direitos à participação, à informação e à privacidade, previstos na Convenção sobre Direitos da Criança - CDC, que lhe asseguram um papel ativo nos seus cuidados. Método. Este estudo aplica o referencial teóriconormativo dos Direitos Humanos dos Pacientes - DHP aos cuidados em saúde das crianças. Trata-se de pesquisa bibliográfica que se fundamenta nos estudos desenvolvidos por Cohen e Ezer e Albuquerque, precursores na sistematização dos DHP; e nos Comentários Gerais elaborados pelo Comitê para os Direitos da Criança da ONU. Resultados. Sob o enfoque dos DHP, verifica-se que o direito à participação coloca em relevo que a inclusão das crianças no processo de tomada de decisão não deve ser apenas um ato isolado, mas compreende a troca de ideias, opiniões e entendimentos entre a criança e os outros participantes do processo de decisão acerca da sua condição. Isso significa que a criança tem o direito de ser ouvida, de ter sua percepção, vontade e preferências respeitadas, em suma, ser verdadeiramente envolvida na tomada de decisão acerca dos assuntos afetos ao seu corpo e a sua saúde. Quanto ao direito à informação, o parâmetro é o paciente. A divulgação transparente e sensível das informações para as crianças sobre sua doença diminui a ansiedade, aumenta a autoestima, promove o senso de autocontrole e encoraja a criança a aderir ao tratamento proposto. Dessa forma, através de uma linguagem adequada, deve-se fornecer à criança uma descrição da sua condição de saúde e das opções disponíveis de cuidado, bem como dos benefícios e encargos esperados de determinado tratamento. Por fim, o direito à privacidade apresenta um conteúdo bastante amplo e traduz-se, de modo geral, no direito de consentir ou recusar cuidados e no direito à confidencialidade dos dados pessoais. Observa-se que deste direito deriva o direito à autodeterminação do paciente que se materializa no processo de consentimento informado. Embora o consentimento das crianças seja um dos temas mais controversos, reconhece-se a existência de várias pesquisas demonstrando sua capacidade para consentirem sobre sua saúde e seus cuidados. Diante disso, ainda que se possa discutir acerca da idade ideal para que a criança seja a responsável pela decisão final, seu direito de influenciar o processo do consentimento, como um dos aspectos do direito à privacidade, deve ser resguardado. Conclusão. Conclui-se que a criança tem direitos que lhe asseguram um papel central nos seus cuidados em saúde de modo que sua vulnerabilidade específica não lhe retira os direitos à participação, à informação acessível, e à privacidade. Assim, independentemente da sua capacidade jurídica, seu engajamento nos seus cuidados é imperativo ético-jurídico a ser incorporado à legislação brasileira e à prática cotidiana dos profissionais de saúde.

\section{REFERÊNCIAS}

[1] Albuquerque A. Direitos Humanos dos Pacientes. Curitiba: Juruá (2016).

[2] Cohen J, Ezer T. Human Rights in patient care: A theoretical and practical framework. Health Hum Rights., 15(2):7-19 (2013) 